\title{
Bilateral cataract: extraction in classic haemophilia with retrobulbar anaesthesia and peripheral iridectomy
}

\author{
L. ROTHKOFF,* B. BIEDNER, AND K. SHOHAM \\ From the Department of Ophthalmology, Soroka Medical Centre, and the Faculty of Health Sciences, \\ Ben Gurion University, Beersheba, Israel
}

SUMMARY A 47-year-old factor VIII deficient haemophiliac successfully underwent bilateral cataract extraction. The use of cryoprecipitates to achieve haemostasis permitted retrobulbar anaesthesia and a peripheral iridectomy without complication. We consider that the use of cryoprecipitated factor VIII concentrate allows safe elective ocular surgery in patients with classic haemophilia.

The danger of haemorrhage in patients with haemophilia has necessitated postponement of elective ocular surgery or the use of special techniques to avoid untoward bleeding. The advent of cryoprecipitated factor VIII concentrate prepared from human plasma has made possible the restoration of normal haemostasis for the entire operative period. Elective ocular surgery can then be performed with the usual techniques. We wish to describe a patient with classic haemophilia who underwent bilateral cataract surgery by means of retrobulbar anaesthesia and peripheral iridectomies, a procedure not previously described in these patients.

\section{Case report}

A 47-year-old male watchmaker was a known haemophiliac since childhood. He had noted steadily decreasing vision in both eyes for the past year. On admission he had visual acuity of hand movements only in both eyes, with normal light projection, 2-point discrimination, and colour perception. Mature cataracts in both eyes prevented fundus examination. Intraocular pressures were normal.

General physical examination was normal. Laboratory findings are shown in Table 1. No evidence of a circulating inhibitor of factor VIII activity was found.

One hour before operation 1600 units of factor VIII concentrate was intravenously infused. Surgery was performed in the right eye by means of retrobulbar anaesthesia and Atkinson facial nerve block. A superior rectus suture was placed. An incision was

*Present address: Eye Institute, Tel Hashomer, Israel.

Address for reprints: Dr B. Biedner, PO Box 151, Beersheba, Israel. made in clear cornea followed by a peripheral iridectomy. Cryoextraction of the lens was performed after the use of chymotrypsin. The corneal wound was closed with interrupted 8.0 silk sutures. No unusual bleeding was noted during the entire operative period. Postoperatively the patient continued to receive 800 units of factor VIII concentrate every 12 hours for 7 days. No haemorrhages were seen in the postoperative period. The patient was discharged 12 days after surgery.

At examination 10 weeks later the patient had 6/9 vision with his aphakic correction, but complained of difficulty working as a watchmaker because of the absence of binocular vision. $\mathrm{He}$ therefore was readmitted for cataract extraction in his left eye.

Preoperatively the factor VIII level was now found to be $7.5 \%$. The other pertinent tests were not significantly different from those shown in Table 1.

Table 1 Results of coagulation tests in our patient

\begin{tabular}{|c|c|c|c|}
\hline Coagulation test & Patient & Normal & Control \\
\hline $\begin{array}{l}\text { Clotting time (Lee and } \\
\text { White method) }\end{array}$ & $21 \mathrm{~min} 5 \mathrm{~s}$ & less than $5 \mathrm{~min}$ & \\
\hline Prothrombin consumption & $26.8 \mathrm{~s}$ & & $15 \cdot 0 \mathrm{~s}$ \\
\hline Fibrinogen $(\mathrm{mg} / 100 \mathrm{ml})$ & 380 & $150-360$ & \\
\hline Platelet count & 248000 & above 200000 & \\
\hline Bleeding time (Ivy method) & $2 \mathrm{~min} 30 \mathrm{~s}$ & $2 \cdot 5-7 \mathrm{~min}$ & \\
\hline Tourniquet test & negative & negative & \\
\hline Partial thromboplastin time & $53.4 \mathrm{~s}$ & & $34.5 \mathrm{~s}$ \\
\hline $\begin{array}{r}\text { Factor VIII assay } \\
\text { (Owen method) }\end{array}$ & $10 \%$ & & \\
\hline
\end{tabular}


Preoperative treatment, operative procedure, and postoperative care were as in the first admission. No abnormal bleeding occurred. However, the first day after operation the anterior chamber was found to have $4+$ cells and fibrin with a small hypopyon. Because of the possibility of endophthalmitis a subconjunctival injection of gentamicin $40 \mathrm{mg}$ was given. No subconjunctival bleeding at the site of injection was observed. The anterior chamber cleared within 24 hours with conservative treatment with atropine, steroid, and antibiotic drops. The subsequent postoperative recovery was uneventful, and the patient now sees 6/12 with his aphakic correction in the left eye. He is satisfied with his binocular vision and has returned to work.

\section{Discussion}

The introduction of cryoprecipitates made it practicable for blood banks to produce factor VIII in concentrated form at a reasonable cost (Pool et al., 1964). The use of this concentrate is now standard in the treatment of classic haemophilia (Dallman and Pool, 1968). Despite this, ophthalmic surgeons continue to use special precautions in cataract extractions in these patients, such as general anaesthesia and omission of iridectomy (Osterlind and Nilsson, 1968; Strauss and Ramsell, 1968; Richards and Spurling, 1973).

Before the introduction of factor VIII concentrates, prolonged bleeding after ocular surgery was a dreaded complication (Rubinstein et al., 1966). The occurrence of a retrobulbar haemorrhage could lead to permanent visual loss (Zimmerman and Merigan, $1960)$. Surgical procedures were to be avoided if possible (Rubinstein et al., 1966). However, since the introduction of cryoprecipitated factor VIII concentrate the approach to elective general surgery has changed (Cooke et al., 1968). We therefore felt justified in attempting cataract extraction in our patient using our standard operating procedure while replacing his deficient clotting factor in the manner outlined by Richards and Spurling (1973). Our only modification was in the use of a corneal section because of the rare occurrence of a hyphaema even months after surgery due to focal vascularisation of limbal wounds (Swan, 1973). In a haemo- philiac such bleeding into the eye would be especially hazardous.

It is worthwhile to note that our patient had what is considered mild haemophilia with factor VIII levels between $7.5 \%$ and $10 \%$. These levels uncommonly cause spontaneous bleeding but are associated with severe and unsuspected bleeding at surgery. Levels of factor VIII activity of at least $25 \%$ are generally regarded as necessary to prevent surgical complications (Wintrobe, 1974). Because of the good results in our patient we feel encouraged to attempt such an approach in other haemophiliacs who until now were discouraged from undergoing elective ocular surgery. This becomes especially meaningful as the life expectancy of haemophiliacs continues to increase with the availability of effective therapeutic materials.

Our thanks to Dr A. Divilansky for the haematological studies and Mrs Bilha Savell for technical assistance.

\section{References}

Cooke, J. V., Holland, P. V., and Shulman, N. R. (1968). Cryoprecipitate concentrates of factor VIII for surgery in hemophiliacs. Annals of Internal Medicine, 68, 39-47.

Dallman, P. R., and Pool, J. G. (1968). Treatment of hemophilia with factor VIII concentrates. New England Journal of Medicine, 278, 199-202.

Osterlind, G., and Nilsson, I. M. (1968). Extraction of cataract in a patient with severe hemophilia A. Acta Ophthalmologica, 46, 171-181.

Pool, J. G., Hershold, E. J., and Pappenhagen, A. R. (1964). High-potency antihemophilic factor concentrate prepared from cryoglobulin precipitates. Nature, 203, 312.

Richards, R. D., and Spurling, C. L. (1973). Elective ocular surgery in hemophilia. Archives of Ophthalmology, 89, 167-68.

Rubenstein, R. A., Albert, D. M., and Scheie, H. G. (1966). Ocular complications of hemophilia. Archives of Ophthalmology, 76, 230-2.

Strauss, L., and Ramsell, T. G. (1968). Successful cataract extraction in a severe haemophiliac. British Journal of Ophthalmology, 52, 242-4.

Swan, K. C. (1973). Hyphema due to wound vascularisation after cataract extraction. Archives of Ophthalmology, 89, 87-90.

Wintrobe, M. M. (1974). Clinical Hematology, 7th Edn, pp. 1165, 1184. Lea and Ferbiger: Philadelphia.

Zimmerman, A., and Merigan, T. C. (1960). Retrobulbar hemorrhage in a hemophiliac with irreversible loss of vision. Archives of Ophthalmology, 64, 949-50. 